\section{Neutrons produced in the Bombardment of Beryllium by Deuterons}

THE purpose of the present measurements was to obtain a thin-target yield-function for neutrons ${ }^{1}$ for the ${ }^{9} \mathrm{Be}(d, n)^{10} \mathrm{~B}$ reaction from 0.7 to $1.5 \mathrm{MeV}$. of deuteron energy.

The neutrons were detected with two Hornyak buttons, $3 \mathrm{~cm}$. in diameter and $1.5 \mathrm{~cm}$, thick (purchased from Isotope Development, Ltd., London), with a magnesium oxide reflector in a thin aluminium box, on $6260 E M I$ photomultiplier tubes. A cathodefollower, a Bell amplifier, an integral discriminator and a scaler were used. The efficiency for fast neutrons, from 0.5 to $5 \mathrm{MeV}$., is about 1 per cent ; for gamma rays it is very low. The geometry used is shown in Fig. 1. The neutron counters were placed as near as possible, so that the angle of detection was $90^{\circ} \pm \mathbf{2 5 ^ { \circ }}$ with respect to the deuteron beam. A CockcroftWalton accelerator with a maximum voltage of 1.5 MeV. was used. The beam of deuterons was deflected through $30^{\circ}$ by a magnetic analyser. The ${ }^{\circ} \mathrm{Be}(p, \gamma)$ reaction was used for calibration.

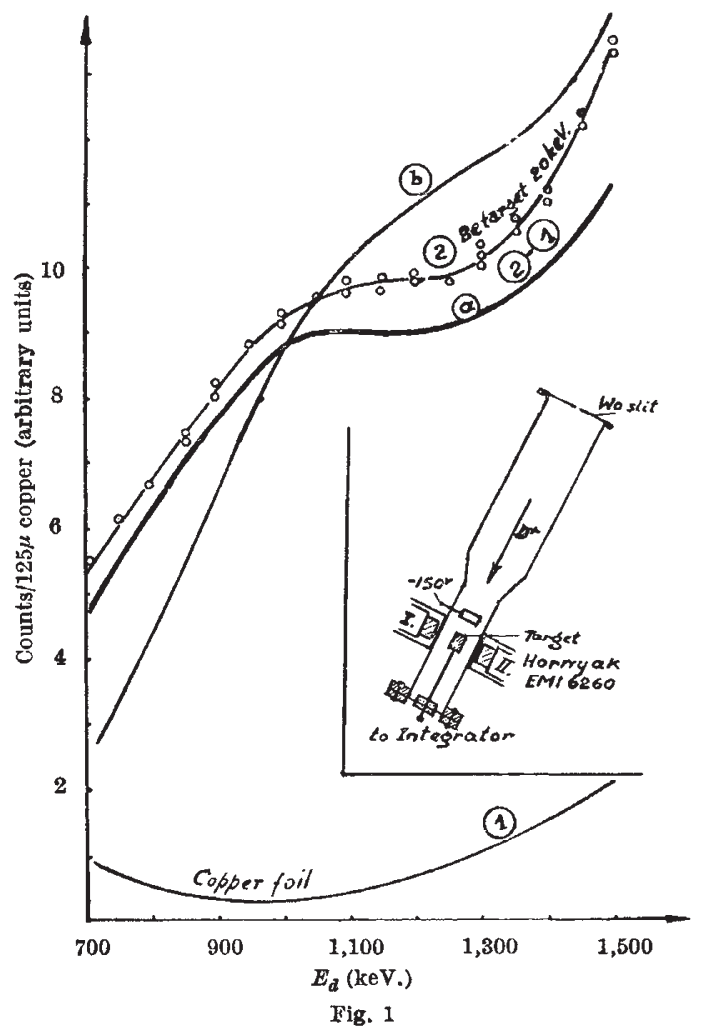

Bombarding currents were measured by a new current integrator with low impedance input (precision better than 1.0 per cent) ${ }^{2}$. The deuteron beam was collimated with a tungsten foil slit. Beryllium targets, $20-60 \mathrm{keV}$. thick, were prepared by evapora tion of beryllium in high vacuum on to a copper foil of $0.05 \mathrm{~mm}$. thickness. Target thicknesses were determined by weighing on a microbalance. Fig. 1 shows the measured excitation curve $(a)$, together with the curve of Evans et al. ${ }^{1}(b)$, taken at $0^{\circ}$. Resonance at $1,000 \mathrm{keV}$. is indicated by the shape of the curve. The mean values of counts of two detectors were always taken and the curve is a result of many repeatied measurements.
Details of this work will be described in the Bulletin of the Boris Kidrich Institute of Nuclear Sciences, Belgrade.

Fedor Boreli

Branislay LaLovid

Boris Kidrich Institute of Nuclear Sciences,

Belgrade.

May 24.

${ }^{1}$ Evans, J. E., Malich, C. W., and Risser, I. R., Phys. Rev., 75, 1161 (1949)

Tjapkin, D., and Ilic, R. (to be described in the Bulletin of the Boris Kidrich Institute of Nuclear Sciences, Belgrade).

sudde, R., and Huber, P., Helv. Phys. Acta, 28, 49 (1955).

\section{Amplification of $1-\mathrm{cm}$. Waves in the Helium Negative Glow}

IN the course of detailed examination of the attenuation of microwaves in the negative glow of an abnormal discharge in helium, we have observed a negative attenuation. This occurs in a very narrow layer near the beginning of the negative glow and is a function of the gas pressure and the current density in the discharge tube.

A discharge tube $50 \mathrm{~cm}$. long with two aluminium electrodes of $5 \mathrm{~cm}$. diameter contained helium at pressures of 1-3 mm. mercury. A low-powered klystron beamed $1 \cdot 25-\mathrm{cm}$. waves at right angles to the discharge tube with the electric vector of the waves parallel to the axis of the tube. The transmitted radiation was detected by means of a crystal detector and a sensitive galvanometer. Changes in attenuation were measured by means of a calibrated precision attenuator. The whole microwave assembly was care. fully aligned and could be moved parallel to the discharge tube. The attenuation, because of the discharge, was measured at each position along the discharge tube as the difference in readings of the calibrated attenuator when the discharge was on and off.

Fig. 1 shows the attenuation in $\mathrm{db} / \mathrm{cm}$. as a function of the distance $d$ from the cathode for a discharge current of $15 \mathrm{~m}$.amp. and a pressure of $2.5 \mathrm{~mm}$. mercury. Near the beginning of the negative

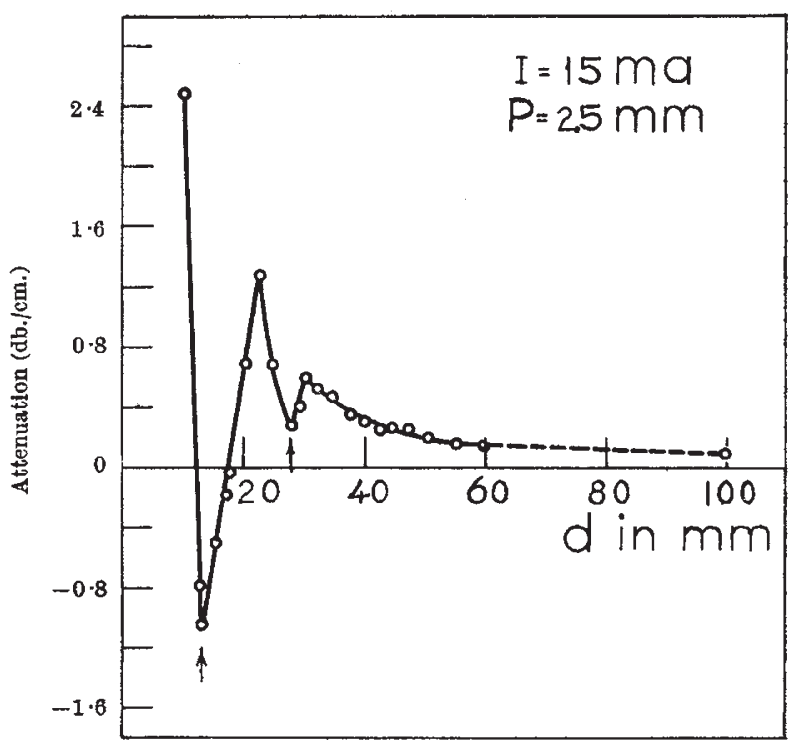

Fig. 1. Attenuation in $\mathrm{db} . / \mathrm{cm}$. as a function of the distance $d$ from the cathode 